\title{
A paixão pelo autômato: a clínica para o cuidado em saúde no templo da tecnologia
}

I ${ }^{1}$ Roberto Henrique Amorim de Medeiros, ${ }^{2}$ Gustavo Caetano de Mattos Mano,

${ }^{3}$ Amadeu de Oliveira Weinmann I

Resumo: A paixão pelo autômato é a expressão que procura problematizar a cultura contemporânea a partir dos efeitos da tecnologia e da ciência no modo de vida capitalista. Inspirado nos trabalhos da atividade de extensão universitária coordenada pelos autores em 2013, na Universidade Federal do Rio Grande do Sul (UFRGS), em que clássicos cinematográficos de ficção científica operavam como mote para as problematizações, este ensaio procura desenvolver o recorte acerca da escuta e do tratamento clínico no contexto de práticas contemporâneas do cuidado em saúde. Ao final, ao trabalhar o problema de saber o que parece elevar o autômato ao status de ideal humano, procura-se traçar uma diferenciação entre técnica e tecnologia para encaminhar série de estudos acerca da automatização nas práticas e relações humanas.

> Palavras-chave: autômato; clínica; saúde; cultura; tecnologia; técnica.

\author{
1 Saúde Coletiva, Universidade \\ Federal do Rio Grande do Sul. \\ Porto Alegre-RS, Brasil. Endereço \\ eletrônico: robertoamorim80@ \\ hotmail.com \\ 2 Universidade Federal do Rio \\ Grande do Sul. Porto Alegre-RS, \\ Brasil. Endereço eletrônico: \\ gustavo.mano@gmail.com \\ ${ }^{3}$ Psicologia, Universidade \\ Federal do Rio Grande do \\ Sul. Porto Alegre-RS, Brasil. \\ Endereço eletrônico: weinmann. \\ amadeu@gmail.com
}


A paixão pelo autômato foi a expressão que nomeou uma atividade de extensão universitária, no final do ano de 2013, cujo objetivo fora envolver alunos e profissionais de variadas áreas de formação, em especial da Psicologia e da Saúde Coletiva, interessados em debater os efeitos do discurso tecnológico cientificista em diversos âmbitos de nossa cultura e sua influência em nossas práticas sociais.

Algumas produções cinematográficas da ficção científica foram selecionadas para aquela atividade, que elegeu como analisador os desdobramentos do autômato como sintoma da modernidade. Dentre as obras escolhidas, encontrase A Invenção de Hugo Cabret (2011), dirigida por Martin Scorsese, que serviu na ocasião como disparador para as problematizações sobre a clínica e a subjetividade contemporânea.

Tendo em vista a natureza do processo de trabalho com as questôes do projeto, optamos pelo ensaio como forma de apresentação, acompanhando as observações de Adorno (1986) acerca do potencial que o ensaio imprime a sua produção teórica ao contemplar o objeto numa proximidade distante o suficiente para não transfigurá-lo com os conceitos. Essa escolha metodológica pareceu-nos adequada ao objetivo de transmitir com o máximo de fidelidade a experiência de produção discursiva que a atividade de extensão proporcionou.

Questóes importantes desdobraram-se ao sabor dos encontros e foram motivo de intensos debates entre os comentadores dos filmes e os participantes do evento de extensão. Dentre outras, evocamos: 1) os reflexos de uma cultura automatizada nas práticas clínicas contemporâneas, expressos na proliferação de protocolos que elidem a singularidade dos pacientes; 2) os impasses da formação clínica, decorrentes do caráter tecnicista por ela assumido, na atualidade; 3) o apreço por uma vida puramente biológica, isto é, desprovida de valor simbólico. Neste artigo, enfatizamos duas questôes suscitadas pelo evento que parecem representar boa parte das problematizaçóes construídas, servindo como guia para as discussões subsequentes entre os autores e posterior elaboração da escrita: em que medida a padronização da técnica, como produto da ação do discurso científico sobre as práticas coletivas, ao procurar excluir o erro, produziu o autômato como ideal? Por conseguinte, será a admiração pelo autômato redenção ou desesperança com o que é da ordem do humano? 
Nada é mais equivocado e reducionista a respeito de uma obra do que aquilo que costuma propor sua sinopse ou a tradução de seu título original. Os exemplos que encontramos no contexto do cinema são os mais evidentes. Algum sensacionalismo e o apelo comercial parecem ser fatores da necessidade publicitária, cuja meta é auxiliar a fazer da obra um produto e facilitar sua venda. Bosco (2007) chamou atenção, por exemplo, para o efeito de esvaziamento da linguagem proporcionado pelo gênero sinopse que frequentemente recalca o aspecto formal da obra a que se refere. No contexto da versão dos títulos dos filmes em língua diversa que a original o efeito se dá pela repetição no tempo: hoje em dia ninguém percebe a cafonice de traduzir The Godfather por $O$ Poderoso Chefão.

A Invenção de Hugo Cabret (2013) é o título em português de um filme premiado recentemente com cinco estatuetas da Academia, ${ }^{1}$ cujo original simplesmente se chama Hugo. Neste caso a mudança de título para o mercado brasileiro supostamente estaria justificada por resgatar o título original da obra literária que inspira o filme (SELZNICK, 2007). Porém, embora não venha contribuir para o esvaziamento da compreensão acerca da proposta artística da obra, essa alteração não deixa de promover um efeito discursivo que, entre outras possibilidades, permite refletir acerca dos objetos privilegiados na circulação de valores da cultura contemporânea e, portanto, acerca da produção do desejo.

Caso perguntássemos àqueles recém-saídos da sala de cinema qual fora, afinal, a invenção de Hugo, provavelmente receberíamos como resposta: o autômato, um boneco dourado, brilhante, cheio de engrenagens e espetacular em $3 \mathrm{D}$, que o protagonista se empenha por consertar, dando prosseguimento ao esforço do pai, que o encontrou, esquecido e avariado, num depósito de museu. Essa hipótese é reforçada na medida em que o menino é apresentado como herdeiro de um saber, que embora prático, lhe confere o perfil de inventor. A habilidade com a montagem dos relógios parece ser rapidamente associada ao conhecimento de física mecânica, cujo paradigma newtoniano ainda serve de modelagem a grande parte das invenções científicas em nosso tempo.

Ao longo da história, somos levados a perceber que o autômato é o elemento narrativo em torno do qual se enlaçam muitas das histórias dos principais personagens do filme, que compartilham uma posição estagnada no tempo 
presente e interrompida com relação ao tempo passado. Se Hugo inventa algo no filme não é, absolutamente, o autômato. $\mathrm{O}$ boneco mecânico fora concebido previamente, tendo seu funcionamento registrado no diário ao qual Hugo recorre. A ambiguidade do título, contudo, promove o surgimento de um lapso que, como nos ensina Freud, é uma porta entreaberta convidando à interrogação. $\mathrm{O}$ que revela esse lapso?

A exemplo de uma nota musical a qual se permite que ressoe o tempo que sua sustentação pelo instrumento durar, propomos que a questão fique a partir de agora suspensa, ressoando durante o tempo suficiente para que se possa esboçar um encaminhamento de resposta. Para tanto, inicialmente tomaremos em análise crítica, com recursos da teoria psicanalítica de Freud e Lacan, a questão do sofrimento contemporâneo e alguns de seus modos de compreensão e tratamento que, fortuitamente, poderá nos aproximar de algum encaminhamento de respostas à problemática do autômato como ideal humano.

\section{A clínica técnica e a ética}

Somos fascinados pela busca de sentidos que expliquem se não toda, boa parte de nossa existência. A falta de sentido, no entanto, é recorrente no tempo de uma vida. Situações de extremo desamparo são casos exemplares em que a impossibilidade de atribuição de sentidos que organizem a experiência promove uma tentativa, quase sempre frustrada, de expressão do que se está passando ou provando. Essa tentativa é o que entendemos por emergência de um sujeito - do padecimento - que impõe àquele que sofre a necessidade de construir uma narrativa de seu padecer.

Conforme o campo do saber ao qual sua narrativa se endereça, pode tornar-se objeto de culpa e dívida, no caso místico-religioso ou patologização e diagnóstico, no caso mítico-científico (ADORNO, 1985). O sujeito do padecimento, em desamparo, se empenha numa narratividade endereçada de seu sofrer com vistas a retomar um estado suposto de felicidade. O referenciamento mais comum é ao campo da clínica que, por sua vez, recorta uma mensagem predeterminada ao traduzir o que é narrado em seus próprios termos linguísticos, de acordo com a trama conceitual com que arma seu modo de escutar o sofrimento do outro. Enfim, cada proposta terapêutica domestica a experiência de sofrimento singular para viabilizar sua prática.

Há, no entanto, uma proposta de ampliação do olhar e da escuta no campo da clínica. Trata-se da clínica ampliada (BRASIL, 2009), que procura levar em 
consideração o maior número de aspectos da experiência de sofrimento com vistas à integralidade do cuidado com o outro. Conceitualmente, é estruturada a partir da conjugação de aspectos biológicos, psíquicos e sociais em harmonia e indissociabilidade nas suas práticas. Mesmo na clínica biopsicossocial que conjuga saberes e procura expandir o olhar e a escuta sobre a subjetividade, observamos processo semelhante ao citado há pouco, por que passam as narrativas. Suas práticas sustentam-se comumente em processos de conversão multidisciplinar do conteúdo da narração que não supera o disciplinar, a não ser no aspecto quantitativo dos processos, o que esvazia a potência interrogante da clínica ampliada e resulta, nesse aspecto, no mesmo status que ocupava a narrativa do sofrimento na clínica tradicional.

Essas condições determinam tacitamente que a forma narrativa construtora da experiência de sofrimento subjetivo seja menos importante que o estabelecimento de uma queixa adaptada ao campo conceitual da clínica a qual se remete. Embora a produção da queixa objetiva - que pode ser entendida como aquela que se deixa domesticar com facilidade pelo saber ao qual se endereça - facilite o nexo com a prescrição terapêutica, aqueles que se valem desse tipo de procedimento clínico quase nunca se questionam a respeito do problema epistemológico de autorreferenciação que ele estabelece: a narrativa adaptada ao campo de saber que se endereça é produzida por enunciados construídos nesses mesmos campos, que, por sua vez, retornam na boca daquele que sofre e, assim, estabelece sua queixa.

O problema da construção adaptada de enunciados por parte daquele que remete seu sofrimento ao saber clínico das evidências científicas, em princípio, não parece ocorrer com a mesma facilidade na clínica psicanalítica. Nela, diversamente, nenhum enunciado efetivo vem pronto pra ser utilizado; há que buscar uma enunciação. A posição de abstinência do analista promove a maturação do momento em que o sujeito toma - rouba - a palavra e instaura um dilema ético: ou procede à transformação da sua língua em discurso próprio, ou assume como verdade um sentido imaginário, pré-fabricado pela linguagem, revelando, assim, sua posição em relação ao Outro. ${ }^{2}$ Ambos por sua conta e risco.

Ainda que na proposta psicanalítica a cura advenha de um convite à enunciação construtora de uma narratividade própria no campo do Outro, não podemos deixar de levar em conta uma espécie de limite. São dois os discursos que copulam perfeitamente na produção do Outro da modernidade, 
das formas de vida decorrentes e seu correlato mal-estar: os discursos da ciência e do capitalismo. ${ }^{3}$

O discurso científico é o patrocinador da promessa de que é possível tudo saber. É um dos agentes, portanto, dos efeitos da ausência da falta na cultura. O discurso do capitalismo, entre outras decorrências, tem a característica paradoxal de não organizar verdadeiramente um laço social. Não valida, por conseguinte, as relações do sujeito com sua história e torna ineficaz a produção da memória. A única relação que promove é a de consumo num reiterado tempo presente.

O sofrimento do sujeito contemporâneo, em sua pluralidade de expressões reduzidas ao patológico biopsicossocial, é, enfim, produto da dificuldade de representar-se em algum lugar possível da copulação discursiva acima referida. Quando o sofrimento é endereçado à ciência, frequentemente a busca é pelo seu nome e seu sentido, pois disso adviria a esperança de alívio imediato e do retorno do bom funcionamento em conformidade com as exigências da vida de cada um. As hipóteses hegemônicas sobre o ser humano de nosso tempo parecem impotencializar suas experiências, temporalidades, formaçôes e dívidas simbólicas com a cultura. Nos seus lugares propõem a vivência, o consumo e o comportamento automático.

A clínica contemporânea, seja ela qual for, costuma ter de enfrentar o protesto subjetivo da depressão, a busca fracassada de adequação ao ideal de si da bipolaridade e a recusa de viver do autismo - três modos de responder a uma falta de representação fundamental no discurso que parece impor ao sujeito uma existência funcional de alto desempenho reiterativo, de respostas corretas e automáticas, de objetividade sem passado ou fantasia. Características que cairiam bem a um autômato. Ou não? Cabe a pergunta: o que se acolhe nas instituiçōes de saúde e nos consultórios, na clínica do sofrimento subjetivo, seja psíquico, social ou físico, seriam autômatos? Ou seriam aqueles que não conseguiram sê-lo?

\section{Automático}

Em dado momento da narrativa fílmica, o protagonista Hugo afirma que, se o mundo fosse como uma máquina, cada um teria que ter uma função nele. Essa frase, provocativa, demanda uma problematização. Ela deve ser tomada puramente no registro utilitário ou a suposta função de cada sujeito pode ser de uma ordem simbólica outra? 
O autômato é o objeto que parece ser causa de desejo no contemporâneo. No cinema, os autômatos robóticos marcam seu ingresso logo nos primeiros anos do século XX. O clássico expressionista Metrópolis (1927) é um dos exemplos mais lembrados. No filme A Invenção de Hugo Cabret, a escolha de um autômato para cumprir o papel de amálgama das histórias dos personagens principais é indício da função que o perfaz como objeto causa do desejo na passagem da modernidade ao contemporâneo. De modo geral, é aos autômatos que se atribui as características de prontidão, eficiência e rapidez ao servir às demandas humanas. Eles são nossos ajudantes incansáveis e precisos, abstinentes e solícitos, dóceis e produtivos. Hoje, talvez também por efeito de repetição, sequer surpreende a ideia de que é do ser humano, na dimensão do trabalho, que se esperam características semelhantes àquelas da natureza dos autômatos.

Condições como essas nos permitem inquirir acerca dos atos e lógicas que sustentam nosso entendimento a respeito da saúde e, fundamentalmente, acerca do que se assume como o sentido da cura. Se a produção de desejo é fruto de arranjos entre os discursos em que nos representamos, o que podemos propor frente às demandas de felicidade por parte daqueles que sofrem? A condição de retornar ao preestabelecido em termos de funcionalidade e desempenho? De que lado está o adoecimento: na inadequação às exigências de apagamento subjetivo ou na resposta satisfatória a essas demandas? $\mathrm{O}$ que propomos aos pacientes, como horizonte da cura, é alguma forma de conserto e reabilitação ao desempenho de uma função específica no mundo? Essas são interrogações que implicam o estabelecimento de outras: quais são os efeitos de uma proposta clínica adaptacionista? E, em decorrência desta última, que formas de vida e que mundo são construídos nessas condições?

As premissas científicas que estruturam a clínica, a bem da objetividade, não possuem verbos no passado, no futuro e nem flexões. São oraçōes afirmativas e condicionais, limitadas à lógica binária - caso dos protocolos que orientam a clínica biomédica e que acabam por influenciar na modelagem dos outros tipos de clínica. ${ }^{4}$ São, pois, orações sem sujeito. As evidências científicas que prometem excluir fatores de confusão e os protocolos que formalizam a boa clínica constituem-se em dois produtos automatizados de nosso tempo. Excluem o erro e, com ele, o sujeito do sofrimento. Resta à ciência catalogar o sofrimento. E servi-lo à exploração pelo mercado. 
Outro fascínio, igualmente tributário da utopia científica do erro zero, é aquele que enaltece aspectos da expertise na clínica do cuidado em saúde. $\mathrm{O}$ processo que paulatinamente procura tornar científico toda a acumulação formal e informal do campo do conhecimento humano vai, assim, produzindo regimes de verdade com consequências diversas. A constituiçẫo de recortes de conhecimento cada vez mais herméticos, ditos especializados, e o desenvolvimento de modos de operar a partir deles, a saber, as técnicas e tecnologias, constituem um par privilegiado do campo científico. Ambos operam no laço social contemporâneo não só como legítimos representantes de uma verdade, mas elementos de consumo no registro das práticas sociais.

Se algo pode ser afirmado categoricamente em meio a tantas problematizações possíveis, é que esteve desde sempre presente no desejo humano o uso de instrumentos que potencializem suas capacidades. $\mathrm{Na}$ cena clássica da primeira parte do filme 2001 - Uma Odisseia no Espaço (1969), o diretor Stanley Kubrick apresenta com maestria um mito fundante da Humanidade: o instante em que o homem primitivo descobre o osso como ferramenta para golpear. Tal instrumento permitirá não apenas o domínio sobre a natureza, gozo característico da condição humana, mas também sobre o semelhante, regozijo este igualmente constitutivo dessa condição, embora bem menos confessável.

Desde o osso até a sofisticação tecnológica dos materiais e aparelhos eletrônicos, a automação segue potencializando capacidades humanas. Ao mesmo tempo em que os aparelhos e as próteses facilitam a vida, criam uma estética do viver, compartilhada a seu modo por cada cultura na era global, cujos efeitos vão engendrando os rumos da vida e dos valores nela privilegiados. Redirecionando esse foco sobre as clínicas, cabe interrogar se, em vez de situar o acento nas técnicas e na manipulação dos suportes tecnológicos, não renderia melhores frutos à formação do profissional em saúde - mas também a formação profissional superior em geral - se dela não fosse extirpada a importância da construção crítica de uma hipótese sobre sujeito contemporâneo? Um melhor uso dos recursos técnicos e tecnológicos não adviria do desenvolvimento de um compromisso ético também com a dimensão política, para o qual bastaria que cada campo de saber problematizasse suas práticas como produtoras de uma representação humana e de sociedade?

No contexto do espírito de nosso tempo, a biologia, as neurociências e o cognitivismo trouxeram muitos avanços. No entanto, a contrapartida foi uma 
acentuada inclinação no sentido de esvaziar a experiência e aproximar o ideal

humano ao autômato. Que tipo de produção desejante teria sustentado a escolha desse caminho para a ciência?

\section{O trash e o clean}

Independentemente do critério de qualidade artística, o conjunto dos filmes de ficção científica, de modo geral, costuma representar o futuro da sociedade humana de dois modos. Bom número deles nos apresenta um mundo asséptico, enquanto outros, um mundo caótico. A primeira característica é frequentemente patrocinada pelo design arrojado e pela arquitetura clean, mas, algumas vezes, ela também surge na forma de relações sociais e afetivas distanciadas. A segunda, pela escuridão e o caos urbano, não sendo incomum a presença de um mundo paralelo - por vezes extraterrestre ou produzido artificialmente - claro e organizado, onde alguns privilegiados podem viver melhor. Mesmo nessa rápida observação, não passa despercebido que em grande parte da representação futurista do mundo a presença da tecnologia digital ou mecatrônica avançada é elemento frequente.

O que passa despercebido é que o recurso tecnológico como sinônimo de recurso técnico é uma construção discursiva cujo equívoco parece ser da mesma ordem que o apresentado no início deste trabalho acerca do esvaziamento da linguagem. É interessante resgatar a seguinte contribuição de Canguilhem (2012) para chegarmos a uma diferenciação nesse ponto. A técnica não é uma produção originária da ciência. A técnica adveio da relação do homem com a natureza e das dificuldades que esta lhe impõe.

Ao argumentar sobre a questão da técnica, Canguilhem (2012) lembra que os termos engenho e engenhoso trazem uma dupla acepção: de máquina por um lado e de estratagema, por outro. A atividade técnica pode ser um referente do que Hegel chamara de "astúcia da razão" e é mais tributária da prática artesanal do que da ciência propriamente dita. Frente a isso, parece necessária a adição de uma precisão crítica em nosso argumento. Talvez seja mais adequado estudar a paixão pelo autômato e seus efeitos nos modos de vida e nas relações humanas, menos por meio da crítica da técnica nas práticas sociais e mais no complexo da relação coletiva com a tecnologia. De acordo com os propósitos deste artigo de iniciar uma problematização, é possível indicar, por hora, um primeiro caminho analítico. Caminho que se abre ao assumirmos como primeiro foco do problema 
a articulação entre o tipo de construção de modalidades técnicas atuais e a produção tecnológica considerada avançada. A reflexão crítica poderá levar a estabelecer critérios de análise acerca da construção de subjetividades atuais, cujo imaginário parece ser estruturado pelo ideal de funcionamento do autômato.

A produção tecnológica também mereceria lugar específico no conjunto da análise. Em vez de uma produção condizente com os problemas e necessidades fundamentais da vida em dado momento histórico, a tecnologia opera na produção frenética de objetos puramente de consumo..$^{5}$ Também por meio do consumo, a sociedade se organiza e seus indivíduos se subjetivam - processo de subjetivação que, paradoxalmente, os objetifica.

A desnecessidade de sentidos dessa produção pode ser percebida por meio da experiência coletiva com boa parte dos objetos cujo propósito se esgota no ato do consumo e cuja característica comum é serem descartáveis. A produção tecnológica, no contexto da copulação dos discursos da ciência e do capital, é frequentemente produção do dejeto. Não parece ser à toa que um dos problemas cruciais da Humanidade, presente tanto no contexto macro como no microssocial, seja o lixo.

O dejeto é preferencialmente entendido como aquilo que deve ser desprezado, como resto que a nada mais serve. No entanto, embora a imagem de um $i$-mundo não seja difícil de conceber, o dejeto é uma das formas de apresentação do objeto que causa o desejo na cultura (LACAN, 1988). Essa condição do objeto, aprendida com a experiência psicanalítica é, paradoxalmente, aquilo que permite uma conclusão contrária. É da ordem do lixo, do rejeito, do dejeto, daquilo que a ordem discursiva hegemônica renega como resto em determinado momento histórico, poder ser o substrato de invenção de uma novidade no laço social. Não parece ser à toa a denominação de trash a uma vasta produção cultural tanto no cinema como na música.

\section{Invenção}

Qual seria a invenção de Hugo Cabret? Já descartamos a possibilidade de que o boneco mecânico responda a essa pergunta, mas talvez ele possa fornecer algumas pistas. $\mathrm{O}$ autômato reconstruído pelo jovem protagonista é capaz de realizar somente uma operação: desenhar uma Lua caricata fulminada por um projétil. Caso fosse acionado mil vezes, mil vezes produziria a mesma gravura, numa implacável repetição do mesmo. Esse é seu desígnio. 
Hugo, por sua vez, percorre uma história distinta. Após perder os pais, assombrado pelo nefasto destino reservado às crianças órfãs, o protagonista fica sob a inglória tutela de seu tio, responsável pela manutenção do relógio da Gare Montparnasse. Assumindo secretamente seu ofício, o pequeno dedica-se, paralelamente, ao furto de peças para o reparo do boneco inacabado deixado por seu pai, um relojoeiro. A busca por preservar, através da restituição do autômato, o legado paterno é, na narrativa fílmica, o elemento crucial da novela familiar de Hugo. O traço que atravessa a novela familiar pela via da profissão - a confecção e o reparo de relógios - permite interpretar que, mais do que um talento para a mecânica, é transmitido a Hugo algo que confere gravidade ao registro do tempo e de sua passagem. Ao contrário do autômato, condenado à reprodução de formas idênticas, da mola da repetição Hugo é capaz de extrair algo novo - e aqui talvez possamos encontrar a invenção aludida no título. Para o solitário garoto, a produção de enlaces afetivos desenvolvida como efeito da busca pela reconstituição do boneco constitui verdadeiramente a possibilidade de escrever com outras tintas sua própria história. Expertise, técnica, tecnologia ou ética? Qual ou quanto de todas para servir à (re)invenção da vida?

\section{Referências}

A INVENÇÃO DE HUGO CABRET. Direção de Martin Scorsese. EUA: Paramount Pictures, 2011. DVD, $126 \mathrm{~min}$, sonoro.

ADORNO, T. O ensaio como forma. In: COHN, G. (Org.). Coleção Grandes Cientistas Sociais: Theodor Adorno. São Paulo: Ática, 1986.

ADORNO, T.; HORKHEIMER, M. Dialética do esclarecimento: fragmentos filosóficos. 2. ed. Tradução de Guido Antonio de Almeida. Rio de Janeiro: Zahar, 1985.

BLADE RUNNER, O CAÇADOR DE ANDROIDES. Direção de Ridley Scott. EUA, Warner Bros., 1982. DVD, 117 min, sonoro.

BOSCO, F. Banalogias. Coleção Filosófica. Rio de Janeiro: Objetiva, 2007.

BRASIL. I Ministério da Saúde. Secretaria de Atenção à Saúde. Politica Nacional de Humanização da Atenção e Gestão do SUS. Clínica ampliada e compartilhada. Brasília: Ministério da Saúde, 2009.

Ministério da Saúde. Protocolos clínicos e diretrizes terapêuticas.V. 1. Série A. Normas e Manuais Técnicos. Disponível em <http://bvsms.saude.gov.br/bvs/publicacoes/ protocolos_clinicos_diretrizes_terapeuticas_vl.pdf> Acesso em: 13 maio 2014. 
CANGUILHEM, G. O conhecimento da vida. São Paulo: Forense, 2012.

LACAN, J. Os quatro conceitos fundamentais da psicanálise. O Seminário: livro 11. Rio de Janeiro: Jorge Zahar, 1988.

. O avesso da psicanálise. O Seminário: livro 17. Rio de Janeiro: Jorge Zahar, 1992.

METRÓPOLIS. Direção de Fritz Lang. UFA: Alemanha, 1927. DVD, 145 min, mudo.

2001 UMA ODISSEIA NO ESPAÇO. Direção Stanley Kubrick. EUA: MGM, 1969.

DVD, $149 \mathrm{~min}$, sonoro.

SELZNICK, B. A invenção de Hugo Cabret. Trad. de Marcos Magno. São Paulo: SM, 2007.

\section{Notas}

${ }^{1}$ Referência ao prêmio Oscar de 2012, que também é estratégia de marketing impulsionadora das bilheterias dos filmes premiados.

${ }^{2} \mathrm{Na}$ teoria psicanalítica lacaniana, o Outro é o conjunto de elementos simbólicos, reais e imaginários ao qual a posição de sujeito - ou assujeitada - de cada um está referenciada.

3 Referimo-nos aqui à noção de discurso acompanhando a proposta de Lacan (1992), tomando-o como articulação dos laços sociais e dos modos de relação em coletividade, produtor de instituídos e condição de possibilidade dos instituintes.

${ }^{4}$ Para uma vasta gama de exemplos, ver Brasil (2010).

5 Aparelhos, produtos, mas é importantíssimo não perder a dimensão também do consumo de serviços e de práticas, especialmente aquelas produzidas sobre o corpo, em nome da prevenção de doenças e comportamentos saudáveis.

${ }^{6}$ R.H.A. de Medeiros, autor principal, elaborou a pesquisa, redação do argumento original e versão final do artigo. G.C.de M. Mano e A. de O. Weinmann realizaram a revisão crítica do conteúdo intelectual do artigo. 
The passion for the automaton: clinics for health care in the technology temple

The passion for the automaton is the expression that tries to problematize contemporary culture from the effects of technology and science in the capitalist mode of life. Inspired by the works of university extension activities coordinated by the authors in 2013, at the Federal University of Rio Grande do Sul (UFRGS), in which science fiction classic films were theme for problematization, this essay brings the clipping of listening and clinical treatment questionings regarding the context of health care practices. At the end, when working the problem of knowing what seems to elevate the status of the automaton as a human ideal, it traces the differentiation between technique and technology to route series of studies on the automation practices and human relations.

> Key words: Automaton; Clinic; Health; Culture; Technology; Technique. 